\title{
Developmental Course of Hypertension in the SHR-Substrains Susceptible to Hypertensive Cerebrovascular Lesions
}

\author{
Yukio Yamori, Kazuhiko Tommoto, Akira Ooshima, \\ Fumitada Hazama, and Kozo Oкамoto
}

We have maintained spontaneously hypertensive rats (SHR), classifying into 8 substrains since 1970 according to their differences in genealogy, geneticobiochemical characteristics and the vulnerability to cerebrovascular lesions (Okamoto [ed]: Spontaneous Hypertension, 1, 129, 134, 1972 ; Jap Circulat J $36: 461,1972)$. These substrains were studied pathologically by necropsy after natural death, and difference in the findings as well as in the incidence of cardiovascular lesions was noted among them (Hazama et al: Jap Heart J 14: 174, 1973). In the present study the course of the development of hypertension was investigated in these substrains thus bred in order to elucidate the relationship between the severity of hypertension and hypertensive cerebrovascular lesions.

Materials and Methods: $\mathrm{SHR}$ (mainly of $\mathbf{F}_{24-26}$ and partially of $\mathrm{F}_{27}$ ) from 8 substrains, $A_{1}, A_{1}-s b, A_{2}, A_{3}, B_{1}, B_{2}, B_{2}-s b$, and $C$ were examined histopathologically after natural death. The incidence of cerebrovascular lesions was studied on $A_{1}, A_{2}, C$, and the combined $B_{1}$ plus $B_{2}$ substrains. Blood pressure of all these substrains in $\mathrm{F}_{27-30}$ was measured by tail-water plethysmographic method (Okamoto and Aoki : Jap Circulat J 27 : 282, 1963) and also by " tail-pulse-pickup method" using a recently-exploited equipment (USM-105-R, Ueda Electronic Works, Ltd, Tokyo). Indirect blood pressures measured by these 2 methods at the same time were compared in more than 200 SHR and normotensive rats of Wistar-Kyoto (NR) and linear correlation was confirmed $(\mathrm{r}=0.950, \mathrm{Y}=1.03 \mathrm{X}-1.2 ; \mathrm{Y}$ and $\mathrm{X}$ are the indirect blood pressures measured by the latter and the former methods, respectively). Correlation of indirect blood pressure measured by the latter method with direct blood pressure measured through a transducer connected to a carrier amplifier and a recorder (Nihonkohden, RP-3 and RM-20) was examined in unanesthetized adult SHR and NR, 11 of each, through a cannula implanted into the femoral artery. Indirect pressure $(\mathrm{X})$ was thus confirmed to be

From the Department of Pathology, Faculty of Medicine, Kyoto University, Kyoto.

This study was supported by Grant-in-Aid from Science and Technology Agency, from the Ministry of Education and from Japan Society for Promotion of Science. 


\begin{tabular}{|c|c|c|c|c|c|}
\hline Substrains & $A_{1}$ & $\mathrm{~A}_{2}$ & $B_{1+2}$ & C & NR \\
\hline Blood Pressure (mmHg) & & & & & \\
\hline at 5 weeks of age & $139 \pm 7$ & $143 \pm 9$ & $142 \pm 6$ & $140 \pm 6$ & $129 \pm 7$ \\
\hline at 10 weeks of age & $190 * * \pm 3$ & $185^{*} \pm 4$ & $171 \pm 3$ & $172 \pm 5$ & $135 \pm 3$ \\
\hline $\begin{array}{l}\text { Initial Increment of Blood Pressure } \\
(\mathrm{mmHg} / \text { week })\end{array}$ & 10.2 & 8.4 & 5.8 & 6.4 & 1.2 \\
\hline Incidence of cerebrovascular lesions ( $\%)$ & 31 & 28 & 9 & 13 & 0 \\
\hline
\end{tabular}

$A_{1}, A_{2}, B_{1+2}, C$ : Substrains of SHR. NR: Normotensive rats from the closed colony of WistarKyoto. **, *: Significant difference from $B$ or $G$ substrains $(p<0.02, p<0.05$, respectively). $(\mathrm{Mean} \pm \mathrm{SE})$

well-correlated with mean pressure $(\mathrm{Y})$ and systolic blood pressure $\left(\mathrm{Y}^{\prime}\right)$; $\mathrm{Y}=1.03 \mathrm{X}+11.2(\mathrm{r}=0.940), \mathrm{Y}^{\prime}=1.07 \mathrm{X}+38.6(\mathrm{r}=0.914)$.

Results: Blood pressure of $\mathrm{A}, \mathrm{B}$, and $\mathrm{C}$ substrains in $\mathrm{F}_{24-26}$ was not markedly different at the age of 4 months as we reported previously (Jap Circulat $J$ 36 : 461, 1972), although the developmental course of hypertension was not paid enough attention at that time. Our present study revealed that A substrains of $\mathrm{F}_{27-29}$ generations showed significantly higher blood pressure than $\mathrm{B}$ and $\mathrm{C}$ substrains at the age of 10 weeks. As the recent descendant of $\mathrm{A}$ substrains showed such a rather rapid development of hypertension, the developmental course of hypertension in $\mathrm{A}$ and other substrains seemed to be related to the difference in the incidence of cerebrovascular lesions in these substrains as shown in Table. The incidence of cerebrovascular lesions in the recent generations $\left(F_{27-29}\right)$ was not available because some of them were still alive. Therefore, on the assumption that the incidence was not markedly different from that observed in $F_{24-27}$, the correlation between the incidence of cerebral lesions in $F_{24-27}$, and the initial increment of blood pressure in $\mathrm{F}_{27-29}$ was statistically analyzed. The results showed that among these substrains studied there was a significant correlation between the incidence of cerebrovascular lesions and the initial increment of blood pressure from 5 to 10 weeks of age $(\mathrm{r}=0.95)$.

Summary with Discussion: The present study on the developmental course of hypertension in some substrains of SHR with marked differences in the incidence of cerebrovascular lesions clarified that rapidly developed and augmented hypertension was probably related to the higher incidence of cerebrovascular lesions. Accelerated development of severe hypertension in young stage seems to cause greater damage in relatively immature vascular wall and initiate the vicious sequence finally ensuing in cerebrovascular lesions. However, possible involvement of other factors than severe hypertension in the difference of vascular vulnerability in the substrain can not be eliminated and is still under investigation. 